\title{
Interpersonal Communication as a Proposal for Humanization in Effectiveness and Reduction of Costs of Brazilian Public Health
}

\author{
Beatriz Regina Pereira Saeta \\ Research Center in Economic Sociology and Organizations (SOCIUS) \\ Lisbon School of Economics and Management (ISEG) \\ University of Lisbon, Portugal \\ Márcia Mello Costa De Liberal \\ Department of Medicine \\ Discipline of Economics and Management in Health \\ Federal University of São Paulo (Unifesp), Brasil
}

\begin{abstract}
Introduction: As the fundamental basis of interpersonal relationships, it can be verbal or non-verbal, effective communication functions work as a decisive factor in successful public healthcare within thee established budget forecast. Objectives: To carry out a bibliographic review of the studies on the use of interpersonal communication by health professionals in academic articles and publications on the subject to assess the current situation. Method: In addition to bibliographic research, it also aims to elaborate a questionnaire as support to measure the degree of dialogical interaction between health professionals and patients during the consultation and/or treatment situation. Conclusion: Although the content of published research has emphasized the importance of the role of communication, in general, to improve the individuals' perception as a subject and to humanize care, health professionals and students in this area still have a precarious knowledge about the subject a subject that needs more in-depth studies and empirical approaches.
\end{abstract}

Keywords: Health; Humanized Care; Interpersonal Communication; Management; Costs.

\section{Introduction}

Even with all the precariousness of material conditions in public health care in Brazil, it is still possible to seek a form of innovation through the dynamics of implementing an effort of interpersonal communication between doctors and patients during the scheduled appointments and also in cases of emergency. Through the training of employees to promote an interactive, informative and adequate dialogue for each user of the Unified Health System (UHS). It should be possible to make the treatment more efficient and economical for all since they have must be transmitted in a simple language and colloquial all the necessary guidance to clarify the doubts that may arise after the first contact.

This way, it is avoided that a large part of the population served to return to the hospitals and health posts only to know if they are doing the correct thing or if it is normal some kind of reaction to the medication indicated by the doctors and often given initially by the nurses of on duty. The rescue of the understanding of the human being as the holder of psychosocial codes of the linguistics fields involving their behavior and nonverbal expression. It reveals that people are always attentive to these signs that establish the necessary links to the understanding of the message, especially by the way each professional can interact successfully in the contact with patients, knowing how to identify the particularities exposed in the most diverse cases presented.

According to the basic principles of communication theory, there is no neutrality in the exchange of interpersonal messages, so the interactions between health professionals and each patient are unique and exclusive. It is worth mentioning that the communication process has two parts, the information to transmit and the dynamic that develops in the interaction with the interlocutors. The content has related to the cultural referential of emitters and receivers which presents differences between the layman and the professionals. This also occurs in the communication process that may or may not be recognized and perceived by the other in varying degrees of awareness, because of the emotions as feelings have used to express in the same way, but with varying intensity in all human cultures and organizations.

In this sense, to humanize care it is necessary to make the non-verbal code, which speaks of the essence of each, more conscious. The understanding that patients need to have of the health professional must pass in special by the awareness during the process of interpersonal communication. There is not only the commitment to pass content or information as simple as it is, because all communicative effort presupposes a feeling. It means that the way we stand before the other in the process of transmitting has to communicate. 
According to the principles and functions of communication, communicating assertively and appropriately has intended to understand what one wishes to convey to people. We can say that the content that needs to be put together to generate satisfactory results in a given situation. Along with this, health professionals should be empowered to promote a range of ideas at an appropriate level of dialogical interaction with someone who requires help, availability, and knowledge of someone willing to work in this activity segment.

In Brazil, the reforms that culminated in the implementation of the UHS sought to strengthen the Primary Health Care (PHC) program and expand its coverage at the national level. However, although the data show a progressive increase in the supply of activities and services at this level of care, the results are not always satisfactory in general care for the population. After completing the step of increasing PHC coverage, many efforts have currently focused on improving the quality and effectiveness of the services provided. In this sense, governmental initiatives focus on incentives for internal and external evaluations. However, the tools capable of evaluating the processes used to achieve effectiveness at this level of care are still insufficient and not sensitive to the complexity of the interaction required.

For all these previously reported reasons, this article seeks to contribute with a proposal for an interdisciplinary study that covers studies on medical and hospital care, verbal and non-verbal communication, as well as basic notions of cost management in health units. It has expected that from the junction of these areas of knowledge it will be possible to improve and to expand the quality of services provided by the public sphere. It is also necessary to considerate the humanization in the treatment of patients that should be observed and treat from a perspective holistic approach. It means to perform a full evaluation within a broader context and connected in terms of individual habits, work and specific socio-economic conditions of each locality in question.

\section{Literature review}

More than at any other time in human history, effective communication plays a leading role in health care at the individual level and for everybody. Health professionals are often involved in creating, planning, implementing and evaluating programs, campaigns or public policies in their work. According to Ramos and Bortagarai (2012), the term communicate comes from Latin (communicate) and means "to put into common". For Stefanelli (1993), from this definition, it is possible to understand communication as the sympathetic exchange of meaning through symbols, and there must be reciprocity in the interpretation of the verbal or non-verbal message. Whatever the mode of communication, verbal or non-verbal, Araújo, Silva and Puggina (2007) are always present in the therapeutic scene, transmitting conscious and unconscious contents, whose significance has linked to the context in which it occurs.

To Maria Júlia Paes da Silva (2002), a professor of the Medical-Surgical Nursing Department of the University of São Paulo School of Nursing, in the context of health care the role of communication in humanized health care "the very idea of communication presupposes the understanding of the parties involved and we know that there is no understanding without prior understanding". For Schelles (2008), the content of the communication has related to the culture referential the health professional who has a different culture from the layman. It is important to recognize that the more information we have about that person and the greater our ability to correlate this knowledge of the other with ours, the better our performance in the aspect of information and content.

For this reason, communication presupposes information and mastery over what one wishes to communicate, that is, intention, emotion and what has intended with the patient at the encounter situation. It is worth mentioning that the health professional is not always aware that the communication effort goes far beyond the transmission of words to the other person, called verbal communication. However, all forms of human, face-to-face, interpersonal communication also include non-verbal communication, including gestures, physical and facial expressions, among other elements that make up a universe apart from words.

In this way, it is possible to affirm that when dealing with an interpersonal relationship, verbal communication does not operate in isolation. Beyond it, there are factors such as the way one speaks, termed para-verbal. They include the silences and grunts we use when speaking, the pauses we make between phrases and words, as well as the intonation placed in the voice. Still, according to Mesquita (1997), besides the para-verbal, there are also facial expressions, body postures before the other, the way we touch it, the interpersonal distances we maintain with another individual.

For the communication effort to be successful, there must be consistency in words and in all forms of non-verbal communication, which has the purpose of completing verbal communication. Another function of non-verbal communication is the demonstration of feelings. Generally, there is no awareness or voluntary control of this type of signaling. In the case of interaction, for example, when someone appreciates what has been sought, the pupil has an involuntarily and unconsciously dilation. Faced with this characteristic highlighted by data such as this, in the doubt between the verbal and non-verbal messages, people rely on this silent language, which speaks of the essence of the human being, of what we are feeling. 
Very rare are the occasions when a person speaks everything he thinks and what he is feeling, but to a good connoisseur, we are always able to demonstrate what we are feeling because a lot of this nonverbal signaling is not necessarily conscious and does not have voluntary control. Those who have fair skin know, for example, that when they feel ashamed they will blush, regardless of whether or not they want to stay, because this demonstration of shame is independent of the will. Nor are we aware that our eyes shine when we are happy and at peace. It is important to emphasize that signaling has a great value and that it allows the relationship with people to become something positive, effective and harmonious.

According to Caprara and Rodrigues (2004), when patients say what they understand as care, they are reminding healthcare professionals how we should communicate with them and showing the importance of non-verbal communication. It can be done by saying that caring is much more than one act or technique, but an attitude, that is, a positioning of how we stand before the other and how we can understand it as a human being and not just as someone who is ill. They are remembering that the language of the body speaks what, often, the speech itself does not say. They urge health professionals to pay more attention to the face as they approach, and to patient-oriented, non-lateralized posture, asking them to be attentive to interpersonal distances because often the professional asks questions at a distance that prevents them from being outspoken in their responses.

When thinking about communication as a problem, it is essential to understand that conflict arises when we do not have the same ideas, the same perception or the same emotion. Therefore, it is part of human coexistence, of our daily life, but it is easier to solve it when we understand the other's point of view, and we are complementary in verbal and nonverbal discourse. When we are complementary in our action and our speech, we reassure the other, even if we think differently from it, which facilitates us to relate and communicate effectively. For Cunha and Giovanella (2009), if we understand that understanding the other's point of view does not mean having to agree with it, we will be able to perceive that a given situation can be sawed from another angle as well and that communication involves these different forms of perception of the world.

It is, therefore, the task of health professionals to develop effective communication with empathy as a result. Only in this way will we be able to perceive the other's point of view. When talking about humanized care, it is not enough to rescue only what is best in the most beautiful essence of the human. What is important is that there is a total and more coherent rescue of the dimensions of the communication universe. According to Coura, Dantas, and Pinto (2008), there is no quality discourse if the attention has not focused integrally on verbal and non-verbal communication if there is not the availability of being in full contact with the patients to stimulate and to promote the dialogue necessary for a successful treatment.

When we try to transform humanization into indicators, we have to think about the waiting list and waiting times, besides hospital occupancy rates. It is also important to consider the number of courses and training performed, employee satisfaction, infection rate, cesarean rate, the complication rate, and intercurrences, the satisfaction of the patient and his relative, in the image before the public and finally in the loyalty of the client. All these indicators go through the health professional's ability to transform into this service discourse.

For Harzhein et al. (2006), non-verbal communication qualifies human interaction, imparting feelings, emotions, qualities and a context that allows the individual not only to understand what words mean but also to understand the feelings of the interlocutor. Even silence is significant and can transmit numerous messages at any given time. In studies carried out with health professionals, it has verified that they consider important knowledge of non-verbal communication because, without this emotional perception, daily problems and routine can cause professionals to touch without feeling, look without seeing and listen without hearing.

Among the aspects relevant to this analysis is the use of space (proxemics), movement in this space (kinetic) and the use of (taxemic) touch. According to Silva et al. (2000), the use of space is a means of non-verbal communication and influences the interpersonal relationship. Named as proxemic, it studies the social meaning of space and its unconscious structuring. Another means of non-verbal communication is touch or tactical which must be presented in all forms of assistance since it should not be a condition to the performance of scientific-technical procedures and should have the purpose of showing affection, empathy, safety, and closeness to the subject.

To cover many of the aforementioned aspects, several types of research raise the discussion of the importance of understanding non-verbal communication in the interaction of the therapist with users of mental health care in a hemodialysis program and with users in terminal states with sedation in the Therapy Unit Intensive care. This procedure can be also being applied with postpartum women with institutionalized elderly, deaf subjects, ostomy oncological subjects, autistic children and hospitalized foreign patients who ignore or know precariously the verbal language and cultural codes of the place where they are sick. 
Moneia (2002) observes that in all studies, the importance of non-verbal communication in the perception of the subjects' feelings is evident, which plays a fundamental role in health care. Therefore, competence in interpersonal communication - verbal and nonverbal - is a fundamental skill to acquire, which enables excellence in health care. From this perspective, the understanding of communication through non-verbal signals is important mainly for professionals whose action is closely related to the body and the movement, since it contributes in a relevant way to improve the relationships, be they of a personal nature or a professional character.

Health professionals should not forget that their messages have interpreted not only by speech but also by their behavior. In this way, communication can be more effective by becoming aware of the importance of body language, especially regarding proximity, posture, touch and visual contact. When the professional relates to the subject, first, he must listen to what he speaks, secondly, what he does not want to talk about, and, thirdly, what he cannot speaks. Still, in the view of Araújo (2007), health professionals have the task of interpreting the meaning of non-verbal communication that the subject sends, to establish a plan of care adequate to the patient's unique needs.

The passivity of the subjects in their relationship with the health professional can lead them to become just a number, a clinical case, a wound or an injury before a technical look. Therefore, the importance of considering non-verbal communication as a fundamental link in the health care process. Nursing care, doctor's healing, rehabilitation of the physiotherapist, the psychologist's understanding and counseling, or any other action in the care of the human being, without the ability to communicate interpersonally, are impossible a basic instrument for the therapeutic relationship, but a competence or capacity that should integrate the training of the health professional.

Although $65 \%$ of all communication that occurs in interaction is non-verbal. In our society and especially in our professional activities, verbal communication is the most widespread and valued. This is perhaps because non-verbal communication is more time-consuming and requires the interlocutors to be attentive to this type of communication. In research with medical students, it was concluded that although they consider important the knowledge of non-verbal communication increase the bond with the patient and to improve the understanding of this, they have demonstrated not to dominate the concepts, being the interpersonal relationship with the predominantly verbal subject. According to Ordahi, Paoilha and Souza (2007), justifying or not this result is the dilemma of the identity of medicine, in the choice between the coldness paradigm of the current technological and impersonal sophistication and that of the secular and magical interaction of the art of therapeutic care.

In this sense, there is a need to promote a new look in the educational practices of gesture and care with the body, making health professionals who are really concerned with the human being, seek to implement means, instruments, techniques, skills, ability, and competence to provide the patient with the opportunity for a better and lasting quality of life. For the rendering of the assistance to the subject, it is necessary to show affection and attention: to listen, to express an attentive look, to touch and to comfort it. These actions provide a fundamental collaboration to the security, protection, and self-esteem of each. Whereas, in establishing good communication with others, it contributes to the reduction of conflicts and misunderstandings, making relationships more harmonic and reaching therapeutic goals more efficiently and with satisfaction. To do this, the health professional needs to master the aspects involved in non-verbal communication.

The emphasis of the non-technical touch, of the non-directed look at the search for pathologies, of the sincere and fraternal approach, when not loving, has rescued human values that have remained somewhere in the time and space of human history, developed new ways of getting sick. According to Penha and Silva (2009), since the communication focuses on the quality of care provided to the subject, to achieve a satisfactory communication the health professional must be involved and believe that his presence is as important as performing procedures technical.

To do so, it must assume a more holistic view of health, in which there is no separation between body and mind. In the course of history, the body was associated with the soul (Plato, Democrat, Saint Augustine), limited to bodily fluids (Hippocrates), locus of defects and sins (Middle Ages) and sectioned from its relation to the mind. In this sense, the religion and the philosophy hold the study of the mind and the study of the body, seen as a machine, has become an object of study of medicine (Descartes). In Castro, Andrade and Muller's view (2006), the disruption of this mechanistic view of the human body introduced with Freud's psychoanalytic theory and later with the introduction of the psychosomatic term by Heinroth and Alexander, implying a more holistic view on the reason the inseparability of biological and psychological aspects.

According to the holistic perspective, the subjectivity of the user is considered and non-verbal communication has an important role in the therapeutic scene, as an element of access, as well as the verbal language, to the patient's cultural and personal values. As Nóbrega observes (2016, p. 87). 
The solutions I get in my book on health innovation has inspired by solutions already established in other fields. 'I do not study the health sector specifically, but what has already worked in retail, manufacturing, telecommunications, aviation, computing, and services in general. From connections with similar problems in various sectors, I arrive at concrete solutions for chronic patients and (an activity whose importance is notorious, but which no organization offers because it cannot profit financially from it), and other health conditions.

These factors have considered relevant in the establishment of a good interpersonal relationship to humanize health care. It seems, however, a paradox to speak of the humanization of health care, since no one would rationally think that such care could be inhuman. The reality shows that the course of health specialization and the way it was conducted from a model of medical education based on scientific rationalization, with the belief in what is visible, palpable, that can be dissected and delimited numerically, produced a fragmentation of the subject, who receives, in this conception, the denomination of patient.

For this reason, the concern from observation of the nonverbal manifestations of this subject is still modest, as well as the lack of a more in-depth reflection on the role of the therapist's body. As a consequence, the deficiency of non-verbal communication teaching and learning visible in undergraduate and graduate students of health demonstrates the importance of including disciplines aimed at theoretical and practical knowledge of this subject. According to Mello and Camargo (1998), the curriculum of the schools of the future professionals of the health value little the contents related to the humanization of the assistance, while there is a hyper-valuation of the technical contents related exclusively to the biological aspects of the human being.

It is possible to perceive the perception of the future professional of the health through the reflection of the make to understand the user increases. This universe brings new elements that appear for the improvement of the communication of the quality of the health services using the competence and the excellence of the service with nonverbal communication being one of the most significant elements in this expansion process. As Sequeira (2010) affirms, communication is not just a "gift", an innate characteristic of a person - communication TEACHES itself and LEARN. The quality of human interaction is indelibly associated with the quality of communication, so it is an ethical duty of every health professional to know and use the best tools of communication in promoting therapeutic intentions in the relationship.

One of the world's great experts in strategy, Michael Porter looks at a current topic of great importance to individuals, professionals, services and health institutions; the growing difficulties of health systems and patients themselves around the world. According to Beulke (2012), cost management in any type of organization is useful and provides the administrator with a more accurate and expanded view of financial reality, since it allows one to look at another way of looking at the available resources, exaggerations and allocate the resources in the right amount to be applied in the most necessary activities. Cost management aims not only to spend less but also to spend better.

Not enough of the need for cost management at the governmental level in general, in the area of health the situation is not different, because it is quite complex. Composed of various types of procedures and activities and numerous projects carried out within a single organization, it has very original characteristics, which makes the costing work a challenging task. (BEULKE, 2012, p. 581)

\section{Material and methods}

To better define the term and identify its dimensions of the verbal and non-verbal communication process, as well as its importance for an efficient and economical humanized service, the option was to develop a bibliographic review on this topic that involves knowledge in the area of health, linguistics and resource management. The review started with articles and texts indicated by experts in the field. Then, the search for other articles was made, both from the references cited by the authors initially consulted. For the selection of articles, the following criteria were considering: studies or critical analyzes regarding primary care and/or continuity of care in PHC, tending towards the availability of the complete article free of charge.

Another contribution of the study by Haggerty et al. (2003) is the identification of three types of continuity: informational, managerial and relational. Informational continuity is the element that allows the connection of information between different providers for the conduct of care. Both the information regarding the clinical condition and the knowledge about the preferences, values , and context of the patient would be important to assure the attendance to the needs of the individual. Management continuity is especially important in clinically complex or chronic disease that requires the involvement of several providers in the conduct of care. When available, services are offered in a complementary and timely manner. Relational continuity, however, refers to a progressive therapeutic relationship between the patient and one or more providers over time, which offers the perception of a guarantee of future care. 
It is worth mentioning that the creation of a lasting and reliable link through the interpersonal relationship, according to the revised literature, presupposes the establishment of a therapeutic relationship over time, or a continuous interpersonal relationship between patient and caregiver, characterized by trust and responsibility. In Brazil, the National Primary Care Policy considers the link between the primary care teams and the enrolled population as one of the basic principles of this level of care. In any case, this link presupposes, immediately, a good relationship between health professionals and patients through an assertive communication effort.

According to Caprara and Rodrigues (2004), a good doctor-patient relationship involves trust, communication pattern, consideration of the problems reported by the patient and the bio-psychosocial aspects of the patient. According to these authors, the biomedical model, because it is disease-centered and technology-focused, has diminished interest in the patient's experience and subjectivity. Thus, in this model, the patient has not perceived in its entirety. Their psychosocial complaints, when heard, do not take into account. In primary care, health records should include not only clinical aspects but also socio-demographic characteristics, values, and family situation of the patient. These characteristics interfere with the health condition of the patient and may constitute a hindrance to adherence to the recommendations of health professionals.

\section{Results and discussion}

As it was observed in the review of the literature, it is possible to verify the need for an initial survey on the current state of interpersonal communication in health institutions. So that a specific plan for specific demands can be elaborate, according to aspects such as the location, reach and profile of the public user of each service unit. This script is composed of 15 questions, nine of which are adapted from the Brazilian version of the Primary Care Assessment Tool (PCAT) and six of them were create from the present revision, which is the numbers 5, 8, 9, 10, 11 and 12.

Proposal of a scheme to investigate the communication link between patients and professionals of a health unit

. Identification or recognition of the regular source of care

1. Does the unit have a clientele?

2. Is the unit recognized by the population as a place of care for old and new health problems?

\section{Interpersonal relationship}

3. Is the patient regularly seen by the same doctor and/or nurse during routine visits?

4. Do the professionals who care for the patient know the patient's family and social background?

5. In case of doubt about the treatment, can the patient talk to the professional who attends him with regularly? Does each visit outside the marked return count for the resource management system?

6. During the care is there enough time for the patients to explain their doubts and complaints?

7. Are the patient's doubts, complaints and complaints valued? Are they record in the medical record?

8. Does the professional express himself as a human being that willing to listen and to understand to the patient's problems without prejudices and value judgments?

9. Is there room for the patient to discuss their treatment and make decisions together with the practitioner through informal dialogue?

\section{Information Continuity}

10. Our health professionals train to meet patients in a friendly manner, receive him on foot, shake hands and talk firmly in the eye?

11. Are our health professionals aware of the need to use colloquial language to speak to people and clearly explain the technical terms as well as the desired and unwanted effects of prescribed medications and procedures?

12. Do our health professionals inform by the superior sphere about the main geographical and population characteristics of the region where they are working?

13. In the case of specialist referral, do these professionals receive information from the unit that attends the patient regularly?

14. In the case of reference for consultation with specialists or external examinations, is there a return of results to the clinician who attends the patient regularly?

15. Do our health professionals inform when a patient cannot get the intended medication

Source: adapted from the Brazilian version of PCA-tools, tested by Almeida and Macinko (2006). *

*Assigning the clientele means making the Health Unit (HU) team responsible for the subjects living in the geographic area defined for this $\mathrm{HU}$, in the process of territorialization, allowing the effective access and bond of this population to the service, principles of health care. Family Health Program (FHP) - Portal Educação: http://www.portaleducacao.com.br/conteudo/artigos/odontologia/programa.../15810. 


\section{Conclusions}

Based on what has been addressed in this article, it is possible to understand that the adequate communication effort makes up an effective service strategy, which contributes to a great extent to reduce costs in terms of unnecessary service, thus increasing the capacity of new patients within the same structure already offered by a health unit to a specific community. As it is very easy to weaken those who already feel fragile by illness or its consequences, it is difficult to even through a flexible posture to have the merit to strengthen those who feel weak and scared, making each patient feel ready again for to take what is necessary for their recovery.

The health professional must convey the message/image of being a person humble and flexible enough to understand the pain of others. In this form of contact, he must seek to strengthen the healthy and positive side of each, regardless of believing that it is better and smarter, especially from a social and economic point of view, especially when it comes to public service. Therefore, the context of consultation and treatment requires that this professional can convey the feeling that, as a human being, he can understand and establish exchanges using what is best for the patient.

To do so, he must be concerned with sharing his knowledge in the simplest and clearest way possible, thus redeeming the origin and original meaning of the word communication. Non-verbal communication learning is also necessary for a view of its role in inter-subjective interactions at the most varied levels of life, be it personal, social, or professional, enabling the expansion of health care to a more active and well-functioning perspective through holistic care that addresses biological, psychological, social and emotional needs. Among the care researched is the interpretation of the nonverbal communication of the patient subject. Studies on the influence of the verbal and non-verbal communication process performed by paramedics are still scarce and insufficient. Thus, this article emphasizes that new studies are been performed by professionals who work not only with the pathology presented but also with subjects who feel pain and demands for care in all senses.

The proposal presented here is a questionnaire, which can be adapted and directed to conduct surveys with different actors (directors of units, professionals or group of patients). In this proposal, the response options were not contemplated, but the use of a closed questionnaire would facilitate the data treatment and allow the use of rapid assessment strategies with the participation of patient groups. In Brazil, in the scope of primary care, studies that evaluate information continuity are still rare or not widespread. In this sense, the implementation of evaluative practices and monitoring of this attribute will have better effects if it also includes interests capable of impacting the area of cost management, because the better the level of understanding of medical information, the less demand there will be to clarify the doubts treatment, thus streamlining the structure for new cases without burdening.

It should also be taken into account that several factors affect the accuracy and reception of verbal and non-verbal communication. For this reason, it is very important to pay attention to the choice of the vocabulary most appropriate to understand all the details of the treatment by the patients. In the same way, it is necessary to consider the emotions that aroused by the contact with the other and those that the other feels when being in the consultation situation with the health professional in the context of the stereotypes we created during the exercise of the profession. It is still decisive to consider a smile, a gesture of affirmation of the head, the contact of the eyes in the transmission of information, a touch on the arm, the shoulder or the hand, the correct use of silence and the soft voice, are revealed as assertive signs in the interpersonal relationships and communication. Therefore, being a good health professional consists of introducing into everyday life the sensitivity of the artist's relationship with his audience in the practice of humanized care.

\section{References}

Almeida, C.;Macinko, J. (2006) Validação de uma metodologia de avaliação rápida das características organizacionais e do desempenho dos serviços de atenção básica do sistema único de saúde (SUS) em nível local. Brasília: OPAS/Ministério da Saúde.

Araújo, M.M.T. (2007). A comunicação com o paciente em cuidados paliativos: valorizando a alegria e o otimismo. RevEscEnferm USP; 41(4):668-74.

Araújo, M.M.T.; Silva, M.J.P.;Puggina, A.C.G. (2007). A comunicação não-verbal enquanto fator iatrogênico. Rev. Esc. Enferm. USP; 41(3):419-25.

Beulke, R. (2012).Gestão de Custos e Resultado na Saúde. Hospitais, Clínicas, Laboratórios e Congêneres (Português) Capa Comum.

Caprara, A.; Rodrigues, J. (2004). A relação assimétrica médico-paciente: repensando o vínculo terapêutico. Cien. Saúde Cole; 9(1):139-146.

Castro, M.G.; Andrade, T.M.R.; Muller, M.C. (2006). Conceito mente e corpo através da história. Rev. Psicologia em Estudo; 11(1):39-43 
Coura, B.; Dantas, M.B.; Pinto, A.A.G.. (2008) Gestão de Custos em Saúde (Português) Capa Comum.2008, \& 1 mais. Gestão de Custos em Saúde (Português) Capa Comum.

Cunha, E.M.; Giovanella, L. (2009). Longitudinalidade/continuidade do cuidado: Identificando dimensões e variáveis para a avaliação da Atenção Primária no contexto do sistema público de saúde brasileiro, Fundação Oswaldo Cruz, Rio de Janeiro.

Haggerty, J.L.; Reid, R.J.; Freeman, G.K.; Starfield, B.H.; Adair, C.E.; McKendry, R. (2003) Continuity of care: a multidisciplinary review. BMJ [periódico na Internet], [acessado 2007 Jan 18]; 327: [cerca de 3 p.]. Disponível em: http://www.bmj.com/content/327/7425/1219.full

Harzhein, E.; Starfield, B.; Rajmil, L.; Stein, A.T. (2006). Consistência e interna e confiabilidade da versão em português do instrumento de avaliação primária (PCATool-Brasil) para serviços de saúde infantil. Cad. Saúde Pública; 22(8):1647-1659.

Mello, J.B.; Camargo, M.O. (org) (1998). Qualidade na saúde. São Paulo: Best Seller.

Mesquita, R.M. (1997) Comunicação Não-verbal: relevância na atuação profissional. Rev. Paul. Educ. Física; 11(2):155-63.

Moneia, A.C.L. (2002). A importância e a compreensão verbal e não-verbal sob a ótica do graduando de medicina [dissertação]. São Paulo (SP): Escola de Enfermagem, Universidade de São Paulo.

Nóbrega, C. (2016). Inovação em Saúde - Como reduzir custos e melhorar resultados usando uma nova ciência, São Paulo: Bookstart.

Ordahi, L.F.B.;Paoilha, M.I.C.; Souza, L.N.A. (2007). Comunicação entre a enfermagem e os clientes impossibilitados de comunicação verbal. Rev. Latino-Am. Enfermagem; 15(5):965-72.

Penha, R.M.; Silva, M.J.P. (2009). Do Sensível ao Inteligível: novos rumos comunicacionais em saúde por meio do estudo da Teoria Quântica. Rev. Esc. Enfermagem, Universidade de São Paulo; 43(1):13-22.

Ramos, A. P.; Bortagarai, F. M. (2012). A comunicação não-verbal na área da saúde, Revista CEFAC, São Paulo.

Schelles, S. (2008) A importância da linguagem não-verbal nas relações de liderança nas organizações. Rev. Esfera; $\mathrm{ND}(1): 1-8$.

Sequeira, C.A. (2010). Comunicação Clínica e Relação de Ajuda, Comunicação em Saúde - Estratégias para Promoção de Saúde (Português) Capa Comum, São Paulo.

Silva, L.M.G.; Brasil, V.V.; Guimarães, H.C.;Savonitti, B.H.; Silva, M.J.P. (2000). Comunicação não-verbal: reflexões acerca da linguagem corporal. Rev. latino-am. enfermagem. 2000; 8(4):52-8.

Silva, M.J.P. (2002). Comunicação tem remédio: a comunicação nas relações interpessoais em saúde. 3 ed. São Paulo: Loyola.

Stefanelli, M.C. (1993). Comunicação com o paciente: teoria e ensino. São Paulo: Robe. 